PETER BURKE

\title{
Los intelectuales: un esbozo de retrato colectivo
}

U NO de los métodos más obvios de enfocar el tema de los intelectuales y la historia es hablar sobre el lugar en la historia de los propios intelectuales. También es una manera útil de tratar el problema de la definición, los rasgos básicos del retrato de la comunidad intelectual. No tenemos esencia, pero sí historia. Lo que somos depende de lo que fuimos - ya sigamos la tradición o pretendamos romper con la tradición. Más precisamente, ya que las identidades sociales son construcciones, lo que somos depende de lo que pensamos que fuimos.

En todos estos casos, "nosotros" se refiere a los europeos. Me voy a limitar a Europa, a pesar del interés de comparar y contrastar la experiencia europea con la de grupos tradicionales tales como los brahmanes o los mandarines, así como con los intelectuales en el Tercer Mundo actualmente.

La historia de los intelectuales europeos es bien sabida. Quizás se podría decir que demasiado bien, porque la imagen convencional es engañosamente clara. Es preciso que nos desfamiliarizemos de ella. Una visión común de nuestro lugar en el tiempo es que somos los descendientes intelectuales de la inteligentsia radical del siglo diecinueve, que son los descendientes de los filósofos de la Ilustración, que son o una versión secular del clero protestante o los descendientes de los humanistas del Renacimiento. Como puede verse, las dificultades ya están empezando a surgir. Aunque no tengo tiempo más que para resumir esta imagen convencional, intentaré expresar algunas dudas acerca de la misma y tratar unos cuantos problemas que espero sean relevantes para nuestra discusión ulterior.

La imagen convencional parece demasiado simple, en tres aspectos obvios. En primer lugar, no toma suficientemente en consideración el hecho de la variación regional, progresando 
como lo hace de los humanistas italianos a los protestantes alemanes y siguiendo con los filósofos franceses y los radicales rusos. No es fácil ver dónde encaja Inglaterra, o España. Por supuesto que la cultura española difiere de la inglesa en aspectos importantes.

A pesar de las revi: tas - y de los congresos-internacionales la comunidad intelectual es menos una comunidad que una confederación de subculturas locales. Las subculturas no son meramente locales. Más significativa, por lo menos en nuestro siglo, es la división entre las ciencias físicas y las humanidades, las "Dos Culturas" de C.P. Snow, con las "ciencias sociales" creando una tercera más que tendiendo un puente entre las otras dos. Esa es una segunda dificultad ignorada por la descripción tradicional.

Una tercera objeción que se plantea a la presentación convencional de la comunidad intelectual es la suposición de su continuidad. Es, como gustan decir los historiadores, una lectura demasiado "contaminada de presente", en el sentido de examinar el pásado sólo con vistas a encontrar antepasados, buscando gente más o menos como nosotros. Michel Foucault no fue el primeru en ver la problematicidad de la contaminación del presente y de la continuidad, pero sigue siendo el crítico más radical de esos prejuiciós comunes. Sería útil preguntarnos cómo sería una hipótesis foucaultiana de los intelectuales, y en qué medida diferiria del tradicional retrato colectivo.

La manera más concreta de contestar a la pregunta es resumir y criticar simultáneamente la descripción tradicional. Para que los problemas resalten con más nitidez, intento contar la historia al revés, no para parecer moderno o post-moderno, sino para producir un Verfremdung-Effekt, para convertir a lo familiar en extraño.

Miremos cincuenta años atrás. Era una época de consideroble preocupación por la identidad de los intelectuales. 1937 fue el año de la muerte de Gramsci, que había estado meditando sobre este problema, entre otros, en su celda. El año inmediatamente anterior Karl Mannheim había publicado su "Ideología . Utopía", con su famosa reflexión sobre los intelectuales "colgando del vacio", freischwebenie Intelligenz. A los pocos años Florian Znaniecki, Joseph Schumpeter y José Ortega y Gasset publicarían sus reflexiones sobre el papel social de los intelert $u$ ales. Unos años antes Julien Benda, Alfred Weber y Max Wı her habían publicado sus ideas sobre el tema Le traisan des cl iss, 
Wissenschaft als Beruf y demás. Muchas de esas discusiones, aun siendo fascinantes, parecen ahora remotas, incluso ajenas. Estos hombres tenían un sentido mucho más fuerte de una comunidad intelectual que muchos de nosotros hoy. Muchos de ellos definieron esa comunidad en contraste con las "masas" (palabra común en aquel momento), y ahora parecen extremadamente "elitistas" (palabra que no existía aún en 1937, por lo menos en Inglés). La gran excepción es por supuesto Gramsci, quien escribió que "todo el mundo es un intelectual", tutti gli uomini sono intelletualli, aunque muchos hombres no desempeñan la función de intelectuales. Tras estas discusiones del rol social del intelectual no es dificil descubrir un sentido de crisis.

Otro salto hacia atrás en el tiempo nos lleva a mitad del siglo diecinueve, a los años de la década de 1860 , cuando el término intelligentsia. ${ }^{*}$ La intelligentsia se veía a sí misma como ajena (de forma muy parecida a lo que pensaban los artistas "bohemios"). En este momento el grupo no se definía tanto en contraste "con el pueblo" como con la administración, el régimen. Pues éste era el momento del "populismo", del descubrimiento del pueblo y de su cultura por al menos un segmento de las clases medias, ante todo en la Europa central y del este. En otros lugares de Europa sin embargo, el término "intelectual", si es que se usaba, significaba algo bastante distinto. En Inglaterra, por ejemplo, la temprana referencia de Byron a "estos intelectuales" está hecha en un tono de desprecio aristocrático. El nuevo término de Coleridge, "clerecía", que hacía referencia a "hombres sabios, ya sea poetas, filósofos o eruditos" no fue generalmente adoptado. Un nuevo vocablo con algo más de éxitc fue "científico". En Francia la expresión tradicional "hombre de letras" fue aún usada, por ejemplo por Tocqueville, cuando describió cómo en el siglo dieciocho "hombres de letras se pusieron al frente de la política".

Podemos pensar en la Revolución Francesa como "los intelectuales en el poder" y en Voltaire, Diderot y compañía como "los intelectuales en la oposición", pero al hacerlo así estamos consciente o inconscientemente extrapolando analogías con el siglo diecinueve y veinte. Voltaire y su círculo no se situaban tanto en la oposición al antiguo régimen como en una postura de ambivalencia frente a él; no revolucionarios sino reformadores. Tenían ciertamente una identidad de grupo, pero

* Se empezó a usar en Rusia 
se definían a sí mismos como filósofos o como ciudadanos de la "República de las Letras", título de la revista de Bayle a final del siglo diecisiete y un recordatorio del lugar de la prensa periódica -el Acta Eruditorum de Leipzig, las Transactions de la Real. Sociedad de Londres y así sucesivamente- y su papel en la creación de una identidad para un grupo que fuera mayor que el formado por los que frecuentaban un salón, café o sociedad cultural en particular.

Bayle era por supuesto un ministro calvinista exilado en los Países Bajos, y ello es un recordatorio de las conexiones entre los filósofos y anteriores "reformadores", el clero culto protestante. De cualquier modo el paso del celoso Protestantismo al Deísmo o Ateísmo implica una solución de continuidad que el término "secularización" no salva totalmente. Hace veinte años un historiador norteamericano planteó la tesis de que el clero puritano inglés del siglo diecisiete proporciona el primer ejemplo en la historia de "intelectuales radicales" en una sociedad tradicional. La idea tiene su atractivo, particularmente para alguien que ahora enseña en Cambridge, donde tantos de los puritanos fueron educados, y más especialmente para un miembro del Emmanuel College, su gran reducto a comienżos del siglo diecisiete.

En apoyo de esta tesis puede argumentarse que este grupo de clérigos cultos creían apasionadamente en la "reforma" y también que la resistencia a esta reforma llevó a algunos de ellos a la emigración, a otros a la rebelión ahora conocida como la "Revolución Inglesa". Incluso se ha sugerido que la revolución se originó en parte porque no había suficientes puestos de trabajo para todos los jóvenes que habían estudiado en Oxford y Cambridge. Sin embargo, induce a error el llamar a estos hombres "intelectuales alienados" y asimilarlos al modelo ruso de intelligentsia del siglo diecinueve. Su "vocación" no era ni el conocimiento ni la actividad política, que eran simplemente un medio para un fin más alto. Su ideal era el del "santo".

Hay también, y ello resulta bastante irónico, una solución de continuidad entre este grupo de reformadores entusiastas y la "Reforma" de Martín Lutero. Lutero había inicialmente sugerido la abolición virtual del sacerdocio como algo exclusivo del clero, es decir, el sacerdocio de todos los creyentes. Su colega en la universidad de Wittenberg aún más radical que él, Andreas Karlstadt, llegó incluso a sugerir la abolición de los títulos 
académicos. Sin embargo, los Protestantes deseaban un clero que predicara, lo que quería decir un clero culto, lo que implicaba un clero más remoto de la gente ordinaria de lo que lo había sido el clero católico medieval.

La discontinuidad entre el clero culto protestante y los humanistas del Renacimiento es aún más acusada, a pesar de la existencia de hombres como Philip Melanchton, que pertenecía a ambos grupos, y el interés por la palabra escrita que éstos tenían en común. La crítica de la razón por parte de los protestantes y su idea de que el saber mundano era "vanidad" les separó de humanistas tan devotos como Erasmo y Vives, y aún más obviamente de hombres como Leonardo Bruni o Poggio Bracciolini. Bruni, Bracciolini y Erasmo no se consideraban primariamente "humanistas" (aunque la palabra humanista sí que existía en el latín de los siglos dieciséis y quince). Ellos se identificaban a sí mismos como litterati, hombres de letras, pensando que era el estudio del lenguaje y de la literatura lo que hacía a los hombres plenamente humanos. Eran críticos culturales, mas no críticos sociales en cualquiera de las acepciones que tenga la palabra "social".

Estos litterati se definieron a sí mismos por contraste con los scholastici, los "hombres de la escuela". En cuanto a éstos, prefirieron considerarse a sí mismos, desde el siglo doce al quince, como "filósofos". Antes del surgimiento de las universidades, desde el siglo doce en adelante, es considerablemente más difícil decidir qué individuos o grupos cuentan como intelectuales. lo cual nos recuerda la estrecha relación que hay entre la. historia de las instituciones y la historia de las ideas.

Espero que este esbozo revele al menos algunas de las dificultades implícitas de realizar un cuadro colectivo de los intelectuales, o incluso - ya que ellos no querrán posar inmóviles para su retrato-perfilar algún tipo de pintura en movimiento acerca de ellos. La imagen y el ideal de una comunidad intelectual, una respublica litterarum, ha sido durante mucho tiempo potente, pero debemos recordar que en la práctica esta comunidad se ha visto durante largos períodos de tiempo fracturada, dividida en subculturas y rasgada por crisis. 